\title{
Impact of fabric parameters and properties on a 2D cutting and stitching line
}

\author{
Magdalena Owczarek ${ }^{1, *}$ \\ ${ }^{1}$ Institute of Architecture of Textiles, Faculty of Material Technologies and Textile Design, Lodz University of \\ Technology), Lodz, Poland \\ ${ }^{*}$ E-mail address: magdalena.owczarek@p.lodz.pl
}

\section{INFO}

CDAPT, ISSN 2701-939X

Peer reviewed article

2020, Vol. 1 , No. 1 , pp. $80-87$

DOI:10.25367/cdatp.2020.1.p80-87

Received: 14 July 2020

Accepted: 8 August 2020

Available online: 20 November 2020

\begin{abstract}
The paper presents the influence of fabric parameters and properties on the circle shape precision confectioning in the $2 D$ plane. The properties of textiles affect the fit of the entire product, which is often subject to the subjective assessment of a technologist. In the case of cutting lines made in the twodimensional area, it seems that there should be no problem with its implementation. Unfortunately, in the clothing, furniture, and automotive industries there are difficulties in combining the same and different textile and non-textile materials (leather). There is no objective method of predicting the precision of circle cutting shape, for different types and properties of fabrics. The work analyzes the shape of a circle cutting and stitching line in a two-dimensional area, taking into account selected properties of textiles (surface weight, elongation, relative bending stiffness). It turns out that the different properties of textiles cause, to a greater or lesser extent, the accuracy of a given circle shape. The fabric with the threecomponent composition of raw materials and the highest surface mass, as well as the smallest stiffness and high elongation obtained the highest precision of the circle shape reproduction. The least precision, i.e. the ability to maintain a given circle shape, was obtained in viscose fabric with low surface mass, high stiffness, and the highest relative elongation. Correlation analysis showed a significant relationship between shape and surface mass and the number of warp threads.
\end{abstract}

\section{Keywords}

pattern making,

cutting,

stitching lines,

textiles parameters and properties
(C) 2020 The authors. Published by CDAPT.

This is an open access article under the CC BY-NC-ND license https://creativecommons.org/licenses/ peer-review under responsibility of the scientific committee of the CDAPT. 


\section{Introduction}

The properties of textiles determine the creation of clothing patterns, but also decorative and technical products. Textile properties have an impact on the possibilities of shaping and matching a more or less complicated garment design and estimating the value of construction and technological additions. Estimating the value of additions and the shape of the cutting line is always subject to the subjective assessment of the designer/technologist [1].

The aim of the work cycle and research is to determine objectively quantitative relationships in the field of the impact of parameters and properties of textiles on the clothing patterns. In the first stage of research work, the influence of parameters and properties of knitted fabrics on the structure as well as the product's drapability and fitting were determined [2-4]. Particular attention was paid to the raw material, internal mesh geometry, and structural parameters, which have a decisive influence on the elongation properties and the pressure on the body. It has been shown that individual parameters, properties of a flat textile product, and especially the weakest parameter determine the product's drapability, fitting, and durability.

In the case of fabrics [5,6], important parameters are weight, thickness, stretching, elongation, bending stiffness, shrinkage, draping, and structural parameters of the weave and raw material. Also important are internal thread friction, deformation angles that affect stability, and the ability to shape the spatial form on the body of the human body in real life or during 3D visualization. Parameters contained in KES and FAST systems can be equally useful when forecasting the shape of clothing construction forms [7].

Individual structural parameters of textiles have a huge impact on the deformation and shaping of a given form in 3D space [8]. The shape of forms is also important in building spatial forms [9, 10].

In the case of a cutting line, e.g. a circle made in a two-dimensional area, it seems that there should be no problem with its implementation. Unfortunately, in the clothing, furniture, and automotive industries there are difficulties in combining the same and different textile and non-textile materials (leather). There is no objective method of checking and predicting the precision of obtaining the oval shape of the cutting line, e.g. in the shape of a circle, as well as confectioning accessories for different types of textiles with different properties. In this work, the shape of the structural cutting line of a circle in a two-dimensional area was analyzed, taking into account selected properties of textiles (surface mass, elongation, and bending stiffness). The various properties of textiles will, to a greater or lesser extent, make the shape of the circle evaluated.

This work presents the influence of fabric parameters and properties on the precision of a shape in the process of confectioning oval lines, e.g. a circle shape in a 2D plane. The purpose of these tests is to determine the ability to maintain a given oval shape of the cutting line at the given values of additives for various properties of textiles.

\section{Methods}

Five samples of plain weave fabric (Fig. 1) differentiated by parameters and properties were used in the experiment. These are fabrics for various purposes, from viscose lining 1_P, to viscose fabric for blouses 2_P, to clothing fabrics 3_P - 5_P with a higher surface mass and more stable than lining and blouse fabrics. This diversity in terms of one weave will show differences in the behavior of the shape of the circle sewn in from the same fabric.

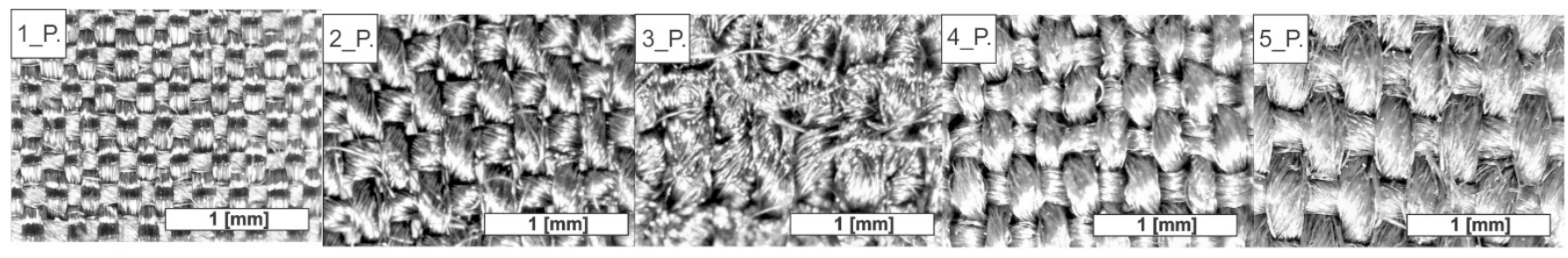

Fig. 1 Fabric samples for the experiment. 
Fabrics are differentiated by the following parameters: raw material, surface mass, weft, and warp density. Their properties of bending stiffness by the loop method and relative elongation under normal conditions at $20{ }^{\circ} \mathrm{C}$, humidity $65 \%$ [11] were also examined (Table 1 ).

The bending stiffness of the loop method determines the falling value of the strip of fabric tied into a loop. So, if the belt falls more, it has a higher value in $\mathrm{mm}$, that is, the fabric has less rigidity.

Table 1. Fabric parameters and properties

\begin{tabular}{|c|c|c|c|c|c|c|c|c|}
\hline \multirow[b]{2}{*}{ fabrics } & \multicolumn{6}{|c|}{ parameters } & \multicolumn{2}{|c|}{ properties } \\
\hline & $\begin{array}{l}\text { raw } \\
\text { material }\end{array}$ & $\begin{array}{l}\text { type } \\
\text { of } \\
\text { weave }\end{array}$ & $\begin{array}{l}\text { type } \\
\text { of } \\
\text { material }\end{array}$ & $\begin{array}{l}\mathrm{Mp} \\
\left(\mathrm{g} / \mathrm{m}^{2}\right)\end{array}$ & $\begin{array}{l}\text { D_wp } \\
\text { (threads/dm) }\end{array}$ & $\begin{array}{l}\text { D_wf } \\
\text { (threads/dm) }\end{array}$ & $\begin{array}{l}\mathrm{C} \\
(\mathrm{mm})\end{array}$ & $\begin{array}{l}E \\
(\%)\end{array}$ \\
\hline 1_P & viscose & plain & lining & 78 & 800 & 450 & 15.40 & 19.50 \\
\hline 2_P & viscose & plain & blouse & 116 & 450 & 300 & 15.90 & 23.00 \\
\hline 3_P & $\begin{array}{l}\text { PET+ } \\
\mathrm{C}+\mathrm{E}\end{array}$ & plain & clothing & 222 & 350 & 250 & 18.10 & 20.00 \\
\hline 4_P & $\mathrm{PET}+\mathrm{E}$ & plain & clothing & 196 & 500 & 350 & 18.10 & 19.50 \\
\hline 5_P & $\mathrm{PET}+\mathrm{C}$ & plain & clothing & 176 & 410 & 250 & 16.50 & 10.50 \\
\hline
\end{tabular}
D_wp (threads/dm) warp density
D_wf (threads/dm) weft density
$\mathrm{Mp}\left(\mathrm{g} / \mathrm{m}^{2}\right)$ surface mass
$\mathrm{C}(\mathrm{mm})$ bending stiffness by the loop method
$\mathrm{E}(\%)$ relative elongation

In the first stage, a circle template was prepared with the location of the sewing and cutting line. Sewing allowance values for a $90 \mathrm{~mm}$ diameter circle are $5 \mathrm{~mm}$ (Fig. 2).

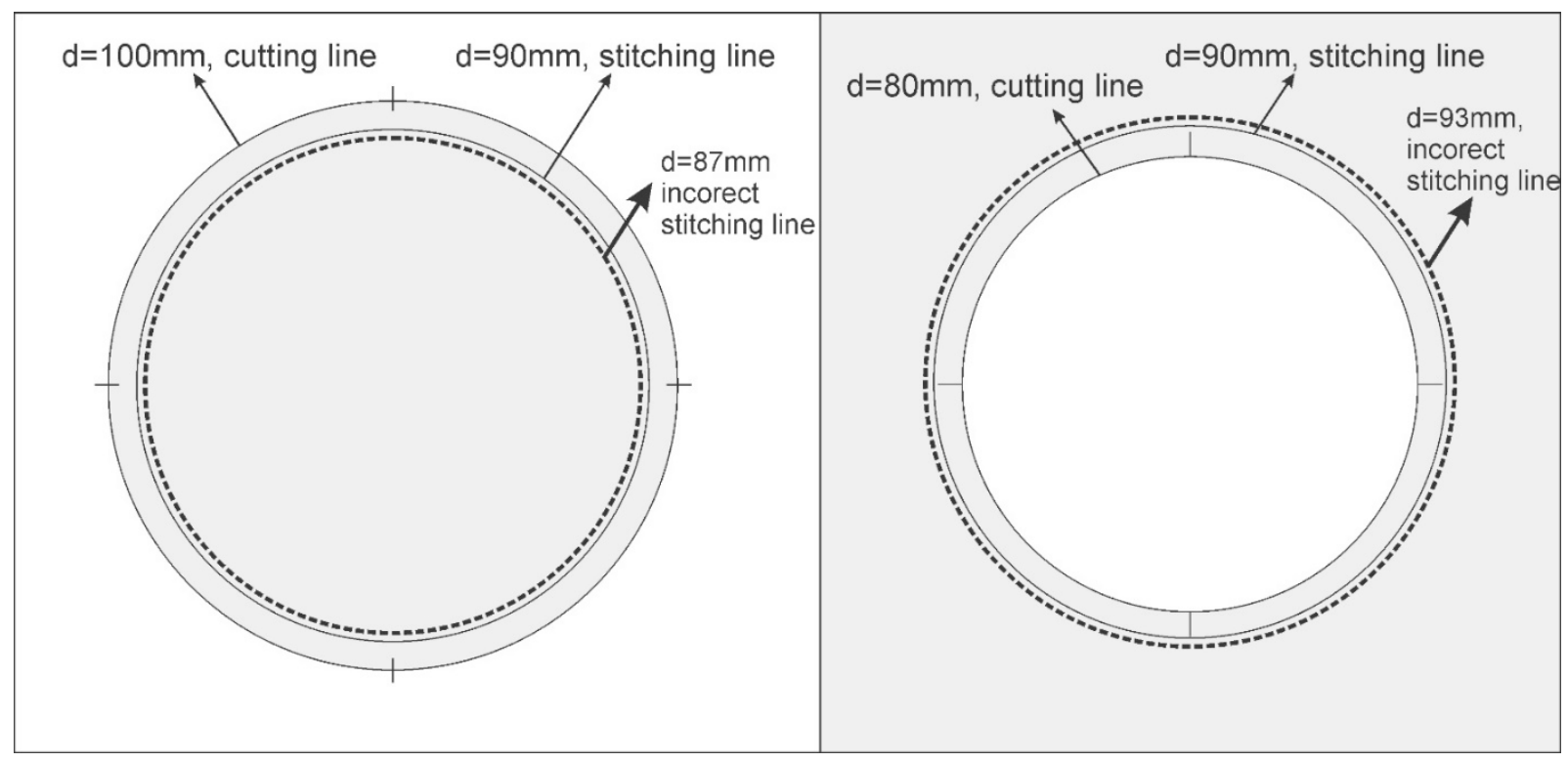

Fig. 2 Pattern of the cutting and stitching lines.

Stitching tests were carried out by the designated sewing lines (Fig. 3a) and with the incorrect setting of the sewing lines (Fig. 3b). The example below shows how the accuracy and the effect of sewing the circle deteriorates. Inaccurate stitching in the sewing line already causes a large distortion of shape and fit. Wrinkles and stretches are visible (Fig. 3). The difference of $3 \mathrm{~mm}$ in the position of the stitching line (Fig. 2) means that part of the circle template has a diameter $d=87 \mathrm{~mm}, \mathrm{~L}=524.38 \mathrm{~mm}$, while part of the plane template has a diameter $d=93 \mathrm{~mm}, \mathrm{~L}=584.04 \mathrm{~mm}$. This is a $59.66 \mathrm{~mm}$ difference in 
matching the circuits. That is why it is so important to accurately identify the stitching lines in this type of shape on a 2D surface.
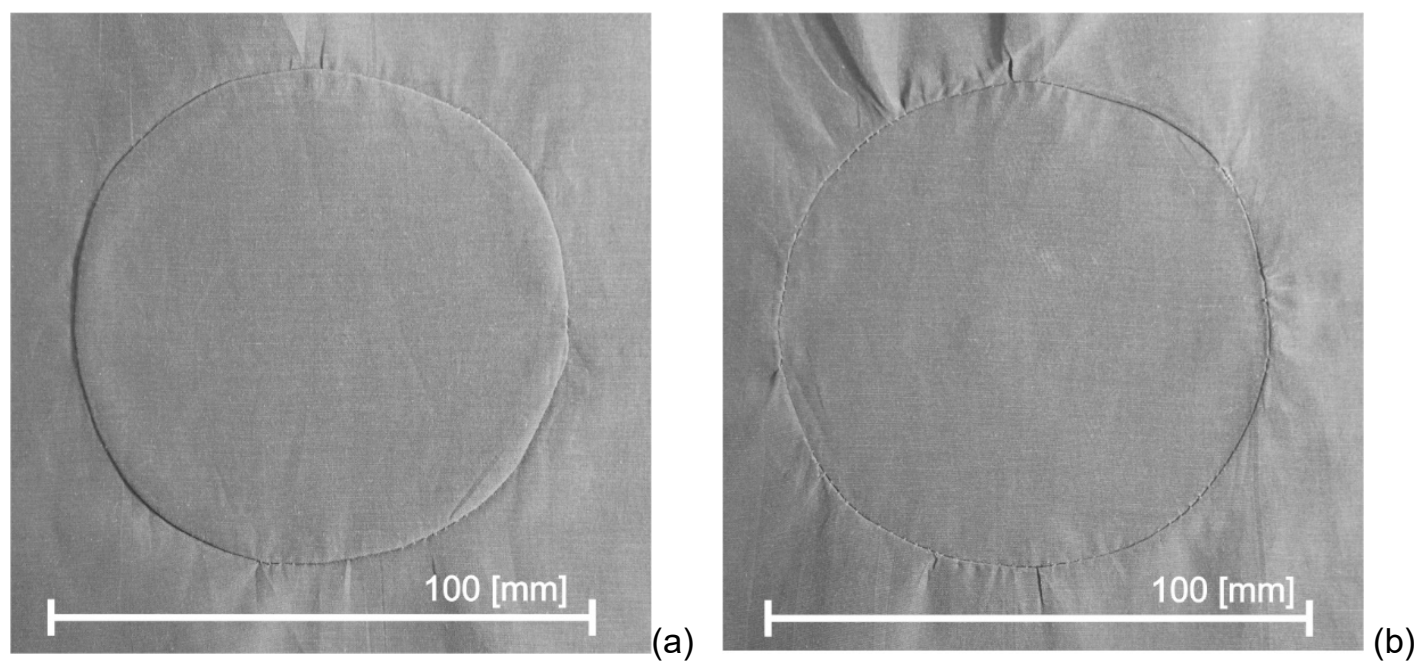

Fig. 3 Samples with changing of cutting and stitching lines.

\section{Test/Data}

For five samples of plain weave, a circle stitching line was made according to the template (Fig. 2). Then the photos of the samples taken were taken with a Nikon Z6 camera with a 24-70 mm lens of $4528 \mathrm{x}$ 3016 in the form of .NEF. The contour of the stitching line was determined on each image of the performed experimental test (Fig. 4).
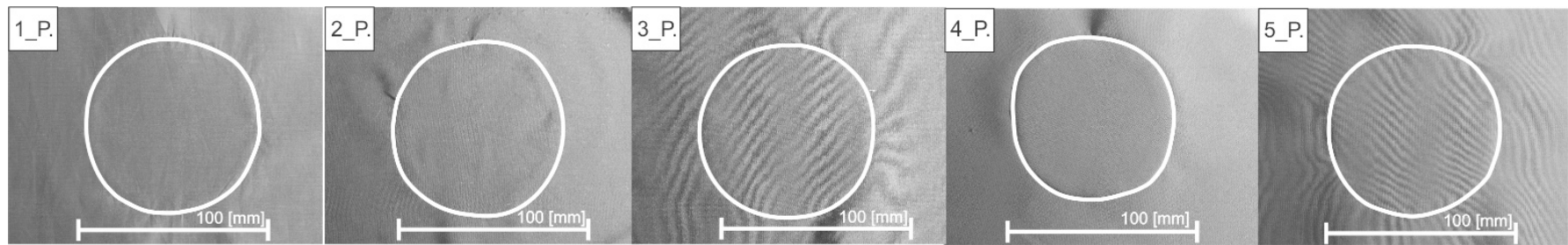

Fig. 4 Fabric samples with stitching lines.

The raw camera images were prepared for processing in the form of a bitmap with a size of $1024 \times 1024$ pixels. The area marked with the stitching contour line was subjected to computer image analysis in the author's MagFABRIC program (Fig. 5).
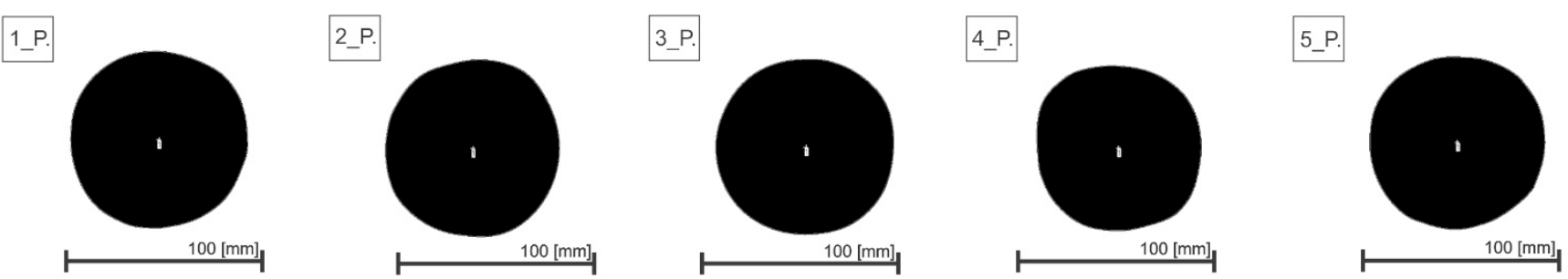

Fig. 5 Image analysis of the stitching lines in the MagFABRIC.

The shape of the stitching line in the experimental tests differs from the ideal shape of the circle. The differences in circumference and shape for all experimental trials are shown in (Fig. 6a). To quantify these differences, a morphometric stitching line analysis was performed in computer image analysis. All experimental trials were described with size and shape parameters. These parameters include circle 
surface area $A\left(\mathrm{~mm}^{2}\right)$, minimum and maximum circle diameters Dmin, Dmax $(\mathrm{mm})$, circle circumference $\mathrm{L}(\mathrm{mm})$ and circle shape parameters dForm (\%) (1), AspectR (2) and FormF (3) (Fig. 6b).
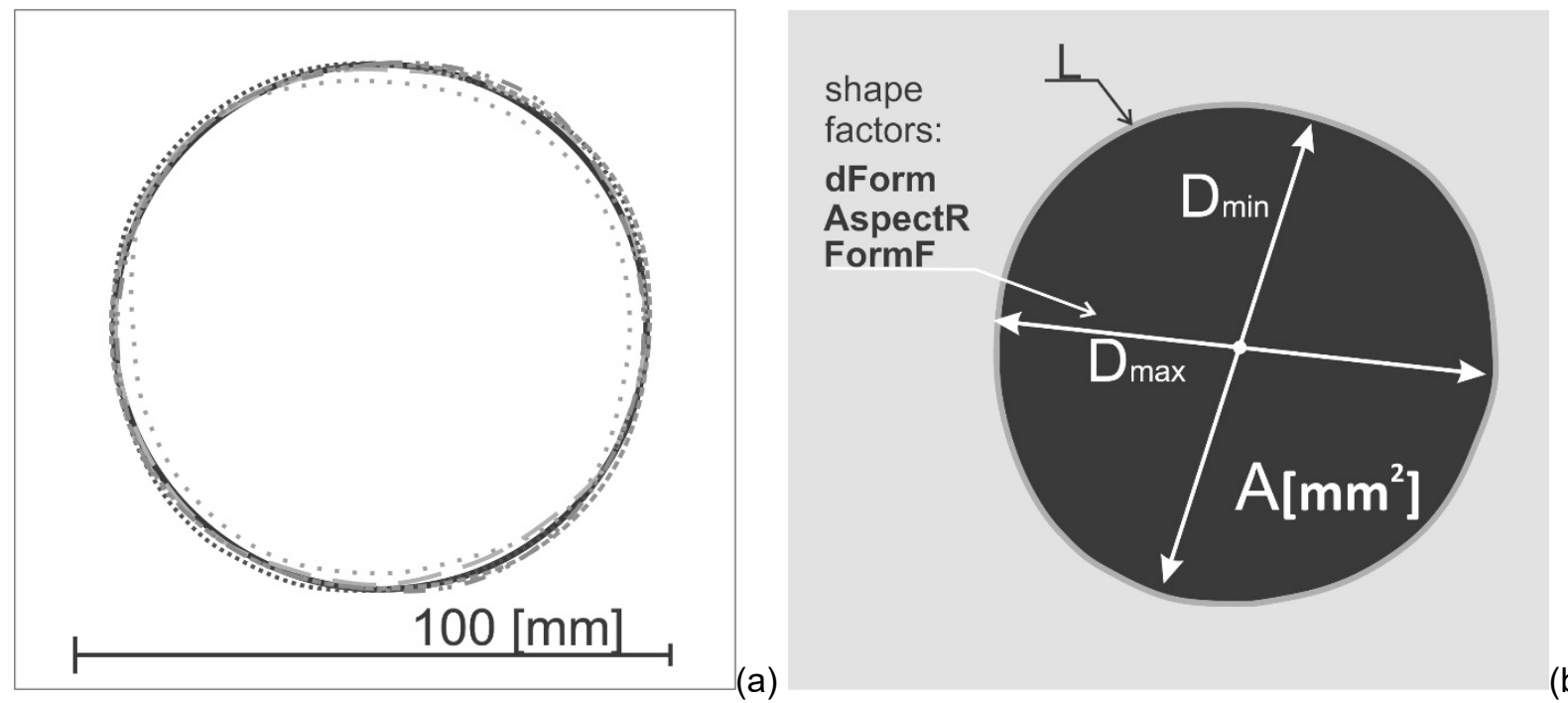

Fig. 6 Morphometrical analysis of the stitching lines: (a) The stitching lines in the fabrics samples, (b) the morphometric parameters of the stitching line.

The circle shape parameters describe three different shape factors that determine the following variation in the shape of the circle field:

- $\mathbf{d F o r m ~ ( \% ) ~ - ~ d e g r e e ~ o f ~ c i r c l e ~ s h a p e ~ d e f o r m a t i o n : ~}$

$$
d F o r m=\frac{D \max -D \min }{D \max } * 100 \text {; }
$$

- AspectR - degree of ellipticity:

$$
\text { AspecR }=\frac{D_{M I N}}{D_{M a x}}
$$

where: Dmin, Dmax (mm) - min. and max. field diameters

- FormF - edge development:

$$
\text { FormF }=\frac{4 \Pi \cdot A}{L^{2}}
$$

where: $A\left(\mathrm{~mm}^{2}\right)$ - surface area, $L(\mathrm{~mm})$ - field circumference - contour.

\section{Results}

The values of the parameters of the morphometric analysis of the size and shape of the circles from the experimental fabric samples are summarized in the following table (Table 2). The experimental tests were combined with a standard sample - the ideal 0_S circle.

From Table 2 and Fig. 7, the thesis is confirmed that the differentiation in the shape of a circle of stitching lines in research samples depends on the parameters and properties of textiles. The 3_P fabric obtained the highest precision of the circle shape mapping by the lowest value of the deformation coefficient $\mathrm{dForm}=4.28 \%$ and the closest value to 1.00 in the case of the ellipticity coefficient AspectR $=$ 0.96 , which indicates a similar shape to the circle. The smallest precision, i.e. the ability to keep the given shape of the circle, was obtained by the 2_P viscose fabric with the highest deformation coefficient $\mathrm{dForm}=9.35 \%$ and the least close to 1.00 in the case of the elliptic coefficient AspectR $=0.91$, which indicates the least similar shape to the circle. The coefficient of the degree of edge development for the $2 \_P$ fabric showed the highest value of FormF $=1.05$ among all research tests. 
Table 2. Results of image analysis of the stitching line of fabric samples.

\begin{tabular}{l|ccccccc} 
Fabrics & $\begin{array}{c}\mathbf{A} \\
\left(\mathbf{m m}^{2}\right)\end{array}$ & $\begin{array}{c}\mathbf{L} \\
(\mathbf{m m})\end{array}$ & $\begin{array}{c}\text { Dmax } \\
(\mathbf{m m})\end{array}$ & $\begin{array}{c}\text { Dmin } \\
(\mathbf{m m})\end{array}$ & $\begin{array}{c}\text { dForm } \\
(\mathbf{\%})\end{array}$ & AspecR & FormF \\
\hline 0_S & 6358.50 & 282.60 & 90.44 & 89.38 & 0.00 & 1.00 & 1.00 \\
1_P & 6251.30 & 277.67 & 91.30 & 86.96 & 4.75 & 0.95 & 1.02 \\
2_P & 5560.19 & 258.42 & 88.69 & 80.40 & $\mathbf{9 . 3 5}$ & $\mathbf{0 . 9 1}$ & $\mathbf{1 . 0 5}$ \\
3_P & 6245.61 & 277.54 & 91.06 & 87.16 & $\underline{\mathbf{4 . 2 8}}$ & $\underline{\mathbf{0 . 9 6}}$ & 1.02 \\
4_P & 6026.71 & 272.98 & 89.38 & 84.72 & 5.21 & 0.95 & 1.02 \\
5_P & 6165.67 & 275.69 & 91.83 & 86.24 & 6.09 & 0.94 & 1.02
\end{tabular}

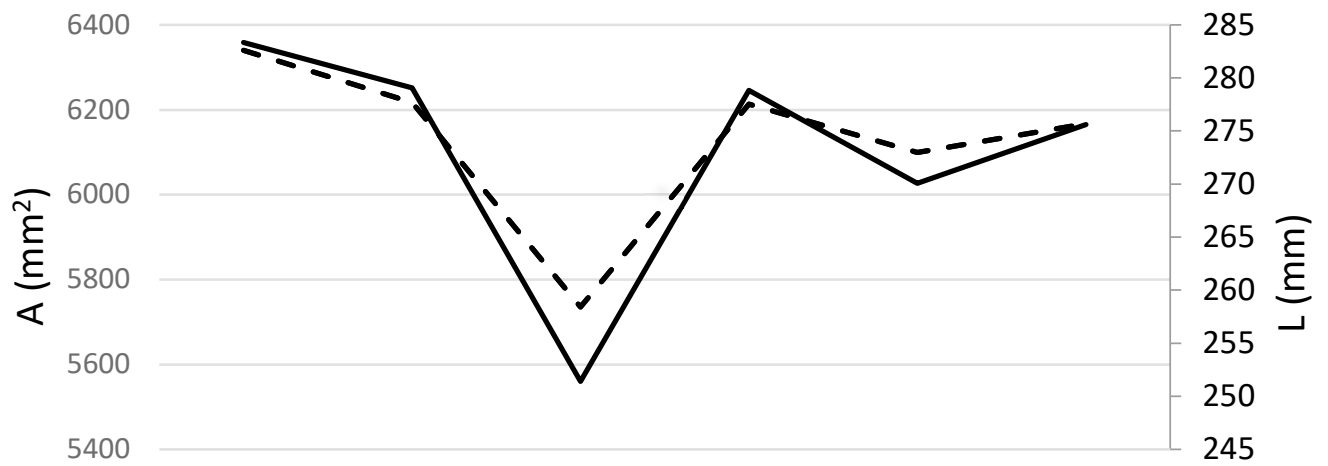

$$
\begin{aligned}
& \text { O_ } \quad \text { 1_P } \quad \text { 2_P } \quad \text { 3_P } \quad \text { 4_P } \quad \text { 5_P } \\
& \longrightarrow \mathrm{A}[\mathrm{mm} 2]---\mathrm{L}[\mathrm{mm}]
\end{aligned}
$$

(a)

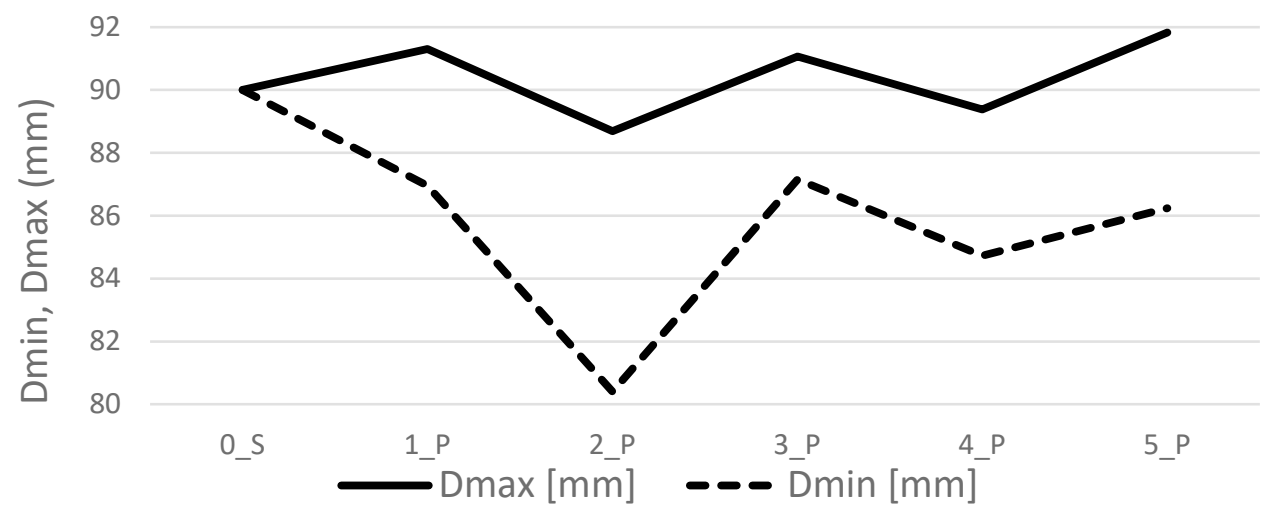

(b)

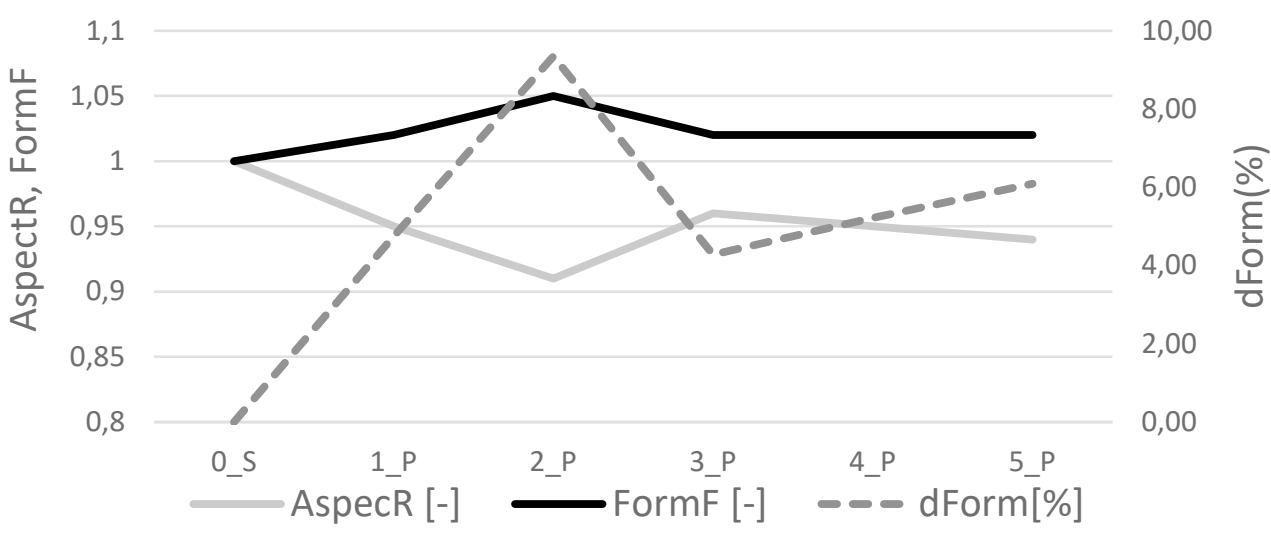

(c)

Fig. 7 Results of the stitching lines image analysis: (a) area $A\left(\mathrm{~mm}^{2}\right)$ and contour $L(\mathrm{~mm})$, (b) minimum and maximum diameters Dmin, Dmax (mm), (c) shape factors: AspecR and FormF, dForm (\%). 
Taking into account the parameters and properties of fabrics, the 3_P fabric with three component raw material composition and the highest surface mass as well as the lowest stiffness and high relative elongation obtained the highest precision in mapping the shape of the circle. However, the smallest precision, i.e. the ability to maintain the given shape of the circle, was obtained by 2_P viscose fabric with a low surface mass, high stiffness, and the highest relative elongation.

A regression analysis of variable dependent shape coefficients with parameters and properties of fabrics was also carried out. Correlation analysis showed a significant dependence of shape on surface mass and warp density (Fig. 8). The strongest correlation was obtained by FormF - the degree of development of the edges (Fig. 8a). The determination coefficients R, R2, and $\mathrm{R}^{\wedge} 2$, in this case, are 0.998, which means that $99 \%$ of the overall variability of the FormF dependent variable is explained by the model. The standard error of estimation equal to 0.00129 allows for estimating the size of random deviations of the model at a low level. BETA coefficients illustrate the largest dependence of independent variables $\mathrm{Mp}$ and $\mathrm{Mp}^{2}$, regardless of the unit, at levels -8.20 and 8.09 , respectively. However, the t-Student $\mathrm{p}$ level does not exceed 0.05 , therefore the variables $M p$ and $M p^{2}$ are significant. Only the Dwp variable has $p=$ 0.06 , which means an insignificant relationship. The regression model is as follows (4):

FormF $=1.19-0.002 \cdot \mathrm{Mp}+0.00001 \cdot \mathrm{Mp}^{2}-0.00008 \cdot \mathrm{Dwp}$

where: $\mathrm{Mp}$ - surface mass $\left(\mathrm{g} / \mathrm{m}^{2}\right)$, Dwp - warp density (threads $/ \mathrm{dm}$ )

Even greater significant correlation of surface mass and warp density was obtained by the morphometric parameter of the circumference of the circle $L(\mathrm{~mm})$ (Fig. $8 \mathrm{~b})$. The determination coefficients $R, R 2$, and $\mathrm{R}^{\wedge} 2$, in this case, are 0.999 , which means that $99 \%$ of the total variability of the dependent variable $\mathrm{L}$ $(\mathrm{mm})$ is explained by the model. The standard error of estimation of 0.20379 allows for estimating the size of random deviations of the model at a low level. BETA coefficients illustrate the largest dependence of independent variables $\mathrm{Mp}, \mathrm{Mp}^{2}$, (regardless of the unit), at levels 6.29 and -6.58 and Dwp at 0.66, respectively. However, the t-Student $\mathrm{p}$ level does not exceed 0.05 , therefore the variables $\mathrm{Mp}, \mathrm{Mp}^{2}$, Dwp are significant. The regression model is as follows (5):

$\mathrm{L}=204.28+0.86 \cdot \mathrm{Mp}-0.003 \cdot \mathrm{Mp}^{2}+0.03 \cdot \mathrm{Dwp}$

where: $\mathrm{Mp}$ - surface mass $\left(\mathrm{g} / \mathrm{m}^{2}\right)$, Dwp - warp density (threads $\left./ \mathrm{dm}\right)$

\begin{tabular}{|c|c|c|c|c|c|c|}
\hline Dalej... & \multicolumn{6}{|c|}{$\begin{array}{l}\mathrm{R}=, 99883783 \mathrm{R} 2=, 99767702 \text { Popraw. } \mathrm{R}^{\wedge} 2=, 99070807 \\
\mathrm{~F}(3,1)=143,16 \text { p<, } 06134 \text { Bład std. estymacji: ,00129 }\end{array}$} \\
\hline $\mathrm{Y}=5$ & BETA & $\begin{array}{l}\text { Błąd st. } \\
\text { BETA }\end{array}$ & B & $\begin{array}{l}\text { Błąd st. } \\
\text { B }\end{array}$ & $t(1)$ & poziom $\mathrm{p}$ \\
\hline H. wolny & & & 1,188879 & 012587 & 94,4550 & 006740 \\
\hline G_M & $-8,20764$ &, 542407 &,- 001867 & 000123 & $-15,1319$ & 042010 \\
\hline MP2 & 8,08781 & 492081 & 000006 & 000000 & 16,4359 & 038686 \\
\hline D_HP_TR &,- 98988 & 100121 &,- 000076 & 000008 & $-9,8868$ &, 064173 \\
\hline Dalej... & \multicolumn{6}{|c|}{$\begin{array}{l}\mathrm{R}=, 99992037 \mathrm{R} 2=, 99984074 \text { Popraw. } \mathrm{R}^{\wedge} 2=, 99936295 \\
\mathrm{~F}(3,1)=2092,6 \mathrm{p}<, 01607 \text { Błaqd std. estymacji: }, 20379\end{array}$} \\
\hline $\mathrm{H}=5$ & BETA & $\begin{array}{l}\text { Błąd st. } \\
\text { BETA }\end{array}$ & B & $\begin{array}{l}\text { Błąd st. } \\
\text { B }\end{array}$ & $t(1)$ & poziom $p$ \\
\hline H. wolny & & & 204,2754 & 1,983422 & 102,9914 &, 006181 \\
\hline MP & 6,29919 &, 142024 & 8625 &, 019445 & 44,3531 & 014351 \\
\hline MP2 & $-6,58226$ & 128846 &,- 0030 & ,000059 & $-51,0861$ &, 012460 \\
\hline D_FP &, 65934 &, 026216 &, 0303 &, 001207 & $25,150.5$ &, 025299 \\
\hline
\end{tabular}

Fig. 8 Results the best regression analysis (in Statistica) between fabric parameters and:

(a) shape FormF stitching line; (b) size contour L ( $\mathrm{mm}$ ) stitching line.

\section{Conclusions}

It turns out that the different properties of textiles cause, to a greater or lesser degree, the precision of the given circle shape. The fabric with the three-component raw material composition and the highest 
surface mass as well as the smallest stiffness and high stretchability obtained the highest precision of the circle shape mapping. The smallest precision, i.e. the ability to maintain the given shape of the circle, was obtained by the viscose fabric with a low surface mass, high stiffness, and the highest relative elongation. Correlation analysis showed a significant relationship between shape and surface mass and warp density. The experiment is a preliminary study in the consideration of only one group of plain weave fabrics. It confirms the thesis of the relationship between the shapes obtained, e.g. a circle in a 2D plane, and fabric parameters. This allows you to predict the behavior of fabrics with a specific surface mass in this type of shape. A broader treatment of the issue in the aspect of including a larger group of different fabric weaves will allow us to determine the possibilities in a wider scope. The second aspect extending the scope of research are sewing parameters (sewing speed, type of transport, lubrication, presser foot pressure, thread tension, sewing step) and the type of sewing needle (number, tip) and thread structure (staple fibers, type of core) and sewing thread properties (composition, linear density, twist, twist unevenness), which can have a significant effect on the precision of the shape when cutting and sewing in the two-dimensional area.

\section{Funding}

This research received no specific grant from any funding agency in the public, commercial, or non-profit sectors.

\section{References}

[1] Owczarek, M.; Nawrot, A.; Lukawska, M.; Wereszka, A.; Grzejszczak, L,; Mastalerz, P. Nonstandard Constructional Solutions in Contemporary Clothing Design. Autex Research Journal, 2016, 16 (4), pp. 250255, DOI: https://doi.org/10.1515/aut-2016-0035.

[2] Owczarek, M.; Poliński, Z. Basic properties of the flat textiles in the clothing construction with negative allowance. Proc. of 9th Joint International Conference Clotech'2010, May 27-28 2010, Radom; ISBN 978-837351-377-8, pp. 20-27.

[3] Polinski, Z.; Owczarek, M. Model considerations of flat textile properties in clothing construction with negative allowance. Proc. of 9th Joint International Conference Clotech'2010, May 27-28 2010, Radom; ISBN 978-837351-377-8, pp. 13 -19.

[4] Owczarek, M.; Poliński, Z. Properties of flat textiles in clothing design with negative allowance. Conference Knitt Tech'2010, Rydzyna, ISBN 978-83911012-9-2.

[5] Owczarek, M.; Glinkowska, A. Textiles parameters in clothing constructing. Innovations in clothing technology \& measurement techniques, 10th Joint International Conference Clotech'2012, September 20-21, 2012, Warszawa, ISBN 978-83-7283-492-8, pp. 66-75.

[6] Ancutienè, K.; Sinkevičiūtè, D. The influence of textile materials mechanical properties upon virtual garment fit, Materials Science (Medžiagotyra), 2011, 17 (2), pp. 160-167.

[7] Chajczyk, M.; Owczarek, M. Comparison of parameters related to KES and FAST textiles systems in terms of usefulness in clothes construction. In: Frydrych, I.; Bartkowiak, G.; Pawlowa, M. (Ed.) Innovations in clothing $3 D$ design, products, fashion, technologies, and testing of clothing materials. ISBN: 978-83-7283-8, 2017, pp. 130-136.

[8] Owczarek, M. Susceptibility of the fabric deformation in the design and construction of clothing. Innovative materials \& technologies in made-up textile articles, protective clothing and footwear, Chapter I: Clothing Design And Technology, ISBN 978-83-7283-6666-3, 2015, pp. 66-74.

[9] Owczarek, M.; Chajczyk, M. The comparison of female close fitting bodice patterns of different authors, Innovative materials \& technologies in made-up textile articles, protective clothing and footwear, Chapter I: Clothing Design And Technology, ISBN 978-83-7283-6666-3, 2015, pp.75-80.

[10] Owczarek, M.; Chajczyk, M. Morphometry of clothes construction forms with the application of computer image analysis. Innovations in clothing $3 D$ design, products, fashion, technologies, and testing of clothing materials. ISBN: 978-83-7283-8, 2017, pp. 17-30.

[11] Konecki, W. (red.) Metrologia surowców i wyrobów włókienniczych, Wyd. PŁ Łódź 1996, ISBN 83-86453-49-4. 